\title{
Structural Changes during Mechanical Mixing in Carbon Black-Natural Rubber Systems Studied by Pulsed NMR
}

\author{
Hajime Serizawa, Masayoshi Ito, Tetsuo Kanamoto, \\ Koji TANAKA, and Akimasa NOMURA* \\ Department of Chemistry, Faculty of Science, \\ Science University of Tokyo, \\ Kagurazaka, Shinjuku-ku, Tokyo 162, Japan. \\ * Research \& Development Center, Nippon Zeon Co., Ltd., \\ Yako, Kawasaki-ku, Kawasaki, Kanagawa 210, Japan.
}

(Received September 10, 1981)

\begin{abstract}
Proton spin-spin relaxation time $\left(T_{2}\right)$ has been measured by the pulsed NMR technique for composites of natural rubber and carbon black prepared by Brabender mixing. The amounts and mobilities of tightly bound rubber and loosely bound rubber, which are determined by the free induction decay analysis, change with mixing time. At the first stage of mixing, the amounts of both components increase rapidly and the mobility of the tightly bound rubber decreases. The ratio of the tightly bound rubber to the loosely bound one decreases rapidly with time, reaching a limiting value at the black incorporation time. At the second stage, the amounts continue to increase at a slower rate but the mobilities become independent of the mixing time. At the third stage, no appreciable change occurs in the amount of each component. Thus, the tightly bound rubber appears to be formed very quickly when the rubber segments get in contact with a new active surface of carbon black, followed by the rapid growth of the loosely bound rubber component around the surface of the preformed tightly bound rubber phase.

KEY WORDS Natural Rubber / Carbon Black / Mechanical Mixing / Pulsed NMR / Spin-Spin Relaxation Time / Segmental Mobility / Tightly Bound Rubber / Loosely Bound Rubber /
\end{abstract}

Incorporation of surface active carbon black into various kinds of rubber improves the mechanical properties (tensile modulus and strength) as a result of the interactions between carbon black and rubber segments. ${ }^{1-3}$ When the carbon black is incorporated into rubber by mechanical mixing, a significant amount of rubber becomes insoluble due to the strong interactions induced during mixing. ${ }^{4}$ This insoluble component is usually called "bound rubber." Pulsed NMR studies ${ }^{5-7}$ have revealed that the bound rubber is composed of two phases having different mobility; i.e., tightly and loosely bound rubber phases. The tightly bound rubber phase is formed around the surface of carbon black particles. The thickness of this phase was estimated to be about $4.5 \mathrm{~nm}$ for ISAF grade carbon black, although it changed depending on the nature of carbon black used. ${ }^{8}$ Thus, the pulsed NMR studies provided very important information on the structure of the bound rubber phases produced by mechanical mixing. However, no NMR study has been reported on the structural changes during mechanical mixing. In this work, proton spin-spin relaxation time $\left(T_{2}\right)$ of the bound rubber was measured as a function of the mixing time by the pulsed NMR technique. On the basis of these results, the mechanism of the bound rubber formation during mixing was discussed in terms of the changes in the segmental mobility and the fractions of the tightly bound rubber (short $T_{2}$ ) and loosely bound rubber (long $T_{2}$ ) components. The changes were followed by the mixing torque which is one of the most convenient and sensitive measures of the overall structural change during mixing. 


\section{EXPERIMENTAL}

\section{Samples}

The rubber and carbon black used were pale crepe (natural rubber) and Diablack A (Mitsubishi Chemicals Co. Ltd.) having a particle diameter of about $18 \mathrm{~nm}$ and a surface area of $163 \mathrm{~m}^{2} \mathrm{~g}^{-1}$, respectively. The NMR signal of untreated pale crepe at room temperature indicated the existence of a small amount of a short $T_{2}$ component which seemed to be due to the impurities such as protein. However, this short $T_{2}$ component was not observed after the treatment by a two-roll mill with a tight nip for $10 \mathrm{~min}$. After mastication of this milled rubber for $1 \mathrm{~min}, 60$ parts of carbon black were added to 100 parts of rubber and mixed by a Brabender Plastograph at $120^{\circ} \mathrm{C}$ and $30 \mathrm{rpm}$ for various periods of time.

The amount of bound rubber (tightly bound rubber plus loosely bound rubber) formed during mixing was very small at a short mixing time. Furthermore, for the composite samples as prepared, the difference in $T_{2}$ values characteristic of the loosely bound rubber and the non-bound rubber was too small and only an average of the two $T_{2}$ 's was detected by the present NMR technique. Therefore, the amount of the total bound rubber formed during mixing and the structural change in this component were studied by other techniques. The former was determined by a solvent extraction method as the ratio of the rubber component insoluble in hot toluene $\left(80^{\circ} \mathrm{C}\right)$ to the total rubber contained in a composite. The latter was evaluated from the NMR data as mentioned later. A composite sample was cut into small pieces (about $1 \mathrm{~mm}$ diameter) and immersed in a sufficiently large amount of toluene (about $2 \mathrm{wt} \%$ of a composite to the solvent) at $80^{\circ} \mathrm{C}$ for $24 \mathrm{~h}$ under nitrogen atmosphere. The carbon gel (bound rubber plus carbon black) was separated and suspended in acetone to exchange toluene with the more volatile solvent, and then filtered. The carbon gel was dried in vacuo for at least one week. When the mixing time was sufficiently long, only the non-bound rubber component was extracted; however, for the composites with a short mixing time, some of the carbon black was also transferred to the filtrate. Therefore, the true compositions of the carbon gel and the filtrate in the latter cases were determined by selectively oxidizing the rubber component with hot nitric acid, diluting with water, filtering, and further washing with acetone to remove the oxidation products. ${ }^{9}$

\section{NMR Measurements}

Pulsed NMR measurements were carried out with a JEOL pulsed NMR spectrometer (JSE-5B), operating at $60 \mathrm{MHz}$. The solid echo sequence ${ }^{10}$ provided a good approximation to the free induction decay, from which the proton spin-spin relaxation time $\left(T_{2}\right)$ was obtained. In this study, the width of $90^{\circ}$ pulse and the pulse interval were adjusted to be 2 and $9 \mu$ s, respectively. To improve the signal to noise ratio of the solid echo signal, the decay signals were accumulated by using an Iwatsu DM-701 digitizer and a time-averaging computer. The signals were read out on an $\mathrm{X}-\mathrm{Y}$ recorder. The spin-spin relaxation time $\left(T_{2}\right)$ and the fraction of each component were determined on a microcomputer by fitting the solid echo signal to the Weibull function: ${ }^{8,11}$

$$
h(t)=\sum_{i} h_{0 i} \exp \left[-\left(t / T_{2 i}\right)^{E i}\right]
$$

where $t$ is the time, $E_{\mathrm{i}}$ is the Weibull coefficient, $h_{0 i}$ is the signal intensity of the $i$-th component at $t=0$, $h(t)$ is the signal intensity at $t$, and $T_{2 i}$ is the spinspin relaxation time of the $i$-th component. The fraction of the $j$-th component $\left(f_{j}\right)$ is given by

$$
f_{j}=h_{0 j} / \sum_{i} h_{0 i}
$$

Estimated errors in the values of relaxation time and fraction were in the range of $5-7 \%$, as estimated from the reproducibility of the data. Samples were sealed in a glass tube in vacuo. The sample temperature was regulated to $\pm 0.5^{\circ} \mathrm{C}$ in a nitrogen gas flow thermostat.

\section{RESULTS AND DISCUSSION}

\section{Brabender Mixing}

Figure 1 shows a typical Brabender Plastograph trace for the mixing of natural rubber and Diablack $\mathrm{A}$ at $120^{\circ} \mathrm{C}$ and $30 \mathrm{rpm}$. The curve exhibits two peaks at mixing times of 0 and $2.5 \mathrm{~min}$ as usually observed in Brabender and Banbury mixing. The initial power peak is due to a high torque generated when the ram is forced down. The power then drops due to both the raise in temperature and the volume contraction, followed again by a torque increase 


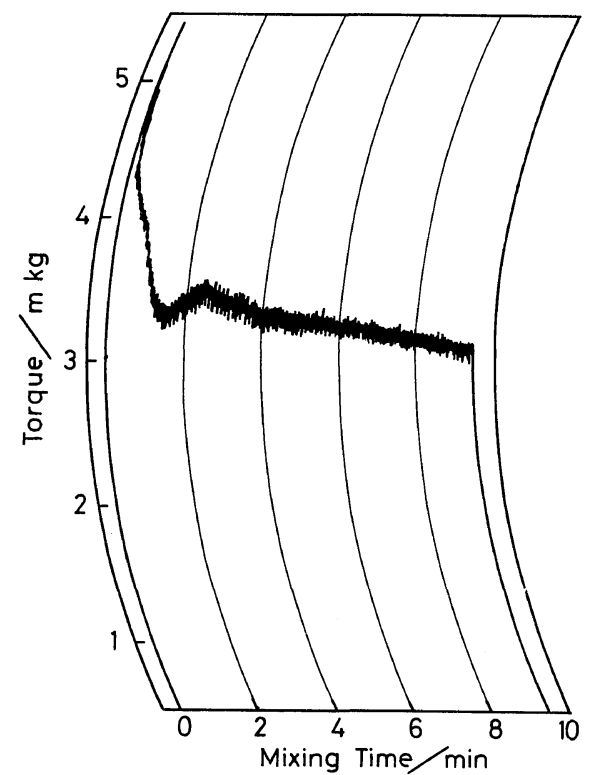

Figure 1. A Brabender Plastograph mixing curve for 100 parts of natural rubber and 60 parts of Diablack A, mixed at $120^{\circ} \mathrm{C}$ and $30 \mathrm{rpm}$.

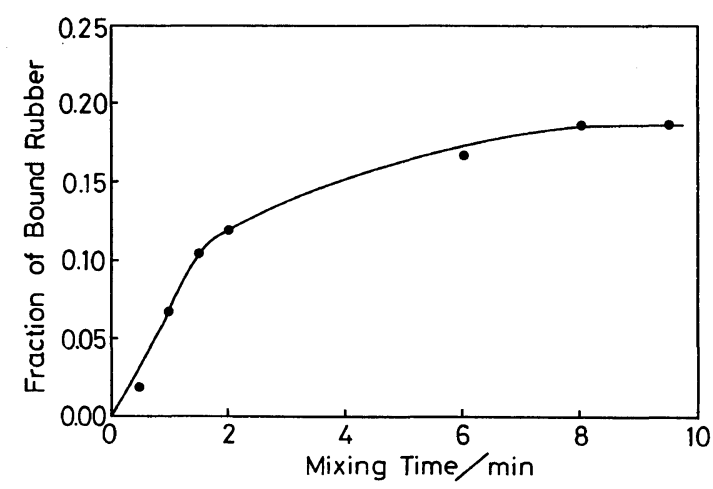

Figure 2. Fraction of the bound rubber component to the total rubber in composites as a function of mixing time.

associated with the viscosity buildup due to the interaction between filler and rubber. The torque reaches a second maximum and then decreases as a result of degradation of the polymer. ${ }^{12}$ The time from the start of mixing to the second power peak, referred to as "black incorporation time" $t$ (b.i.), ${ }^{13}$ is about $2.5 \mathrm{~min}$ for the present case of natural rubber and Diablack A. Therefore, it can be concluded that after $2.5 \mathrm{~min}$ the carbon black is fairly well incorporated and dispersed into rubber, as will be discussed below.

The process of formation of bound rubber during mechanical mixing was followed by the solvent extraction technique. Figure 2 shows the fraction of the bound rubber component to the total rubber in composites as a function of mixing time. The fraction of the bound rubber increases rapidly with time unitl $t$ (b.i.), followed by a gradual increase, and reaches a limiting value of 0.20 at $8 \mathrm{~min}$.

This mixing time dependence of the fraction of the bound rubber is similar to that of the carbon black dispersion studied by Palmgren. ${ }^{14}$ Aggregated carbon black disperses rapidly until $t$ (b.i.) and gradualy approaches a uniform dispersion at a mixing time of $8 \mathrm{~min}$. Therefore, the formation rate of the bound rubber may be primarily governed by an increase in the practical surface area of carbon black which is in contact with rubber segments.

Temperature Dependence of $T_{2}$ and Short $T_{2}$ Fraction

The rubber component in filled rubber is heterogeneous. The tightly bound rubber component, formed around the surface of carbon black $\left(T_{2 \mathrm{C}}\right.$ component), has been successfully detected by NMR technique. ${ }^{5}$ However, the formation process

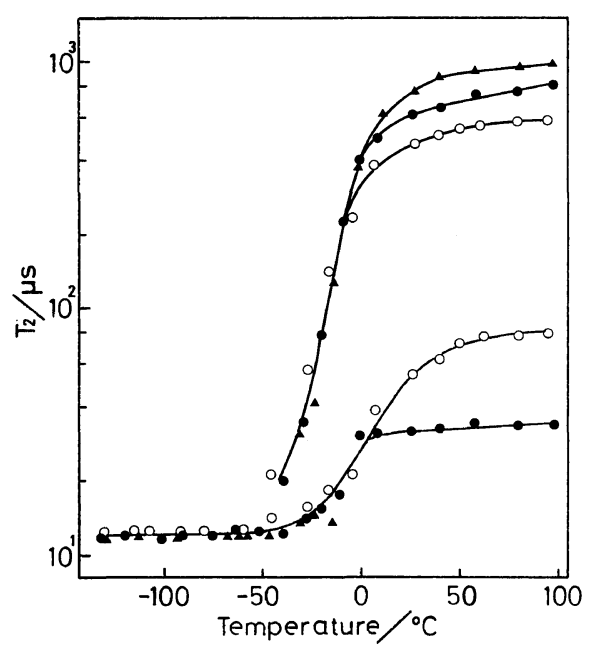

Figure 3. Temperature dependence of $T_{2}$ for composite and carbon gel samples: $\boldsymbol{\Delta}$, composite with mixing time of $9.5 \mathrm{~min}$; from the composite with mixing time of $9.5 \mathrm{~min}$; $O$, carbon gel sample from the composite with mixing time of $0.5 \mathrm{~min}$. 
has not yet been settled. Figure 3 shows the temperature dependence of $T_{2}$ for the composite prepared by $9.5 \mathrm{~min}$ mixing, the carbon gel sample obtained from it, and the carbon gel sample obtained from a composite with a short mixing time of $0.5 \mathrm{~min}$. At low temperatures, $T_{2}$ is about $11 \mu \mathrm{s}$ for all of the samples and stays almost constant up to about $-40^{\circ} \mathrm{C}$. Above $-40^{\circ} \mathrm{C}$, the NMR decay signals of these samples indicated the existence of two $T_{2}$ components. Since in the composite sample, however, the relative signal intensity corresponding to the short $T_{2}$ component was too weak for precise isolation, only the long $T_{2}$ was calculated from the decay signal. In all the samples, both the long $T_{2}$ $\left(T_{2 \mathrm{~L}}\right)$ and the short $T_{2}\left(T_{2 \mathrm{C}}\right)$ increase rapidly from $-40^{\circ} \mathrm{C}$ to $0^{\circ} \mathrm{C}$ due to the onset of micro-Brownian motion $\left(T_{\mathrm{g}}\right)$ of the rubber components. ${ }^{15}$ Although the values of $T_{2 \mathrm{~L}}$ above $40^{\circ} \mathrm{C}$ vary slightly depending on the mixing time (Figure 3), the difference is not very significant. The magnitude of $T_{2 \mathrm{C}}$ is about $25 \mu \mathrm{s}$ above $T_{\mathrm{g}}$, and much shorter than that of $T_{2 \mathrm{~L}}$. Therefore, the short $T_{2 \mathrm{C}}$ component corresponds to the tightly bound rubber in which the segmental mobility is highly restricted by the interactions between carbon black and rubber segments.

The fractions of the $T_{2 \mathrm{C}}$ component, $f_{\mathrm{C}}$, in the carbon gel samples with mixing times of 0.5 and $9.5 \mathrm{~min}$ are shown in Figure 4 as a function of temperature. Since below $T_{\mathrm{g}}$ most of the segmental motions are frozen in, the $f_{\mathrm{C}}$ is 1.0 . From -50 to $-20^{\circ} \mathrm{C}$, the $f_{\mathrm{C}}$ of each sample decreases very rapidly, corresponding to the onset of microBrownian motion in the less restricted regions.

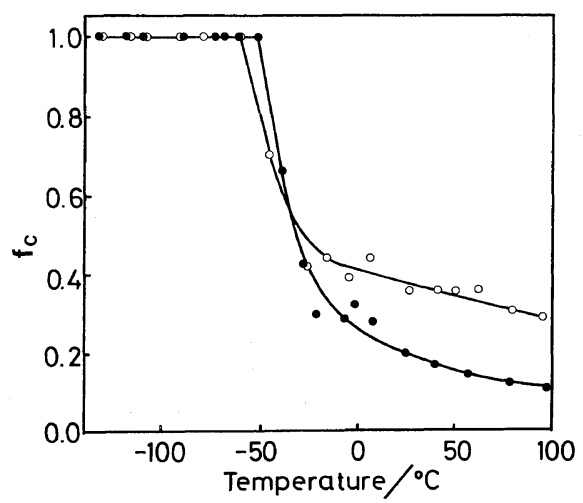

Figure 4. Temperature dependence of the fraction $\left(f_{\mathrm{C}}\right)$ of the $T_{2 \mathrm{C}}$ component in bound rubber (B.R.), symbols as in Figure 3.
Above $-20^{\circ} \mathrm{C}$, the fraction decreases more slowly with increasing temperature even above the melting point of untreated natural rubber $\left(28^{\circ} \mathrm{C}\right){ }^{16}$ This fact indicates that the rubber components in these samples are noncrystalline as was also confirmed by DSC measurements.

\section{Mixing Time Dependence of $T_{2}$ and the Fractions}

Even the carbon gel sample with the shortest mixing time of 0.5 min showed NMR decay signals indicative of the existence of two $T_{2}$ components above $-40^{\circ} \mathrm{C}$. Although the mixing time has large influence on the fraction (Figure 2) and structure (Figures 3 and 4 ) of the bound rubber, the transition temperature in both the tightly and loosely bound rubber components is around $-50^{\circ} \mathrm{C}$ and not significantly affected by mixing time as shown in Figure 3. Since $T_{2}$ for each component does not increase significantly above $30^{\circ} \mathrm{C}$, the structural changes in rubber components during mixing will be discussed based on the $T_{2}$ values at $40^{\circ} \mathrm{C}$ (reference temperature).

Figure 5 shows the $T_{2 \mathrm{~L}}$ and $T_{2 \mathrm{C}}$ at $40^{\circ} \mathrm{C}$ for the composites and the carbon gel samples prepared from them as a function of mechanical mixing time. $T_{2 \mathrm{~L}}$ of the composites is about $780 \mu$ s independent of mixing time. The value is slightly shorter than the $T_{2}(1000 \mu \mathrm{s})$ of the untreated natural rubber but longer than the $T_{2 \mathrm{~L}}$ of the carbon gel $(620 \mu \mathrm{s})$, owing to the presence of the toluene soluble non-bound rubber component. For the carbon gel samples, $T_{2 \mathrm{~L}}$

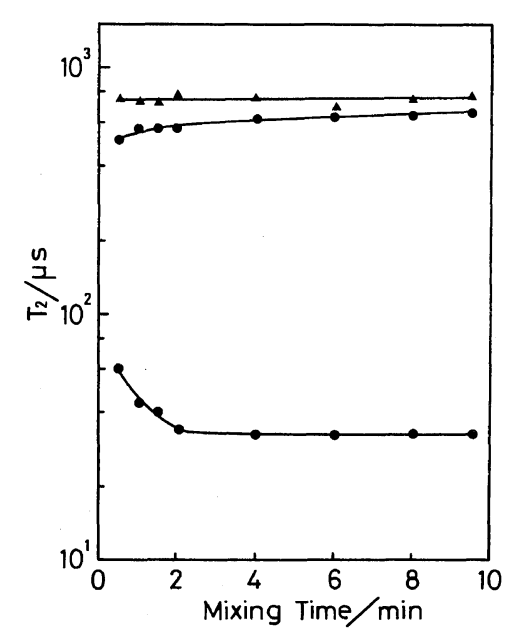

Figure 5. $T_{2 \mathrm{~L}}$ and $T_{2 \mathrm{C}}$ at $40^{\circ} \mathrm{C}$ as a function of mixing time: $\boldsymbol{\Lambda}$, composites and $\boldsymbol{O}$, carbon gel samples. 
increases slightly with increaing mixing time and approaches a constant value of $620 \mu$ s at $t$ (b.i.). In contrast to the $T_{2 \mathrm{~L}}, T_{2 \mathrm{C}}$ decreases rapidly from $60 \mu \mathrm{s}$ at $0.5 \mathrm{~min}$ and reaches a constant value of $25 \mu \mathrm{s}$ at $t$ (b.i.). The limiting value of $T_{2 \mathrm{C}}$ obtained here is comparable to the literature values ranging from 15 to $30 \mu \mathrm{s}$. ${ }^{5,6}$ These measurements of $T_{2 \mathrm{C}}$ and $T_{2 \mathrm{~L}}$ clearly show that at the first stage of mixing the segmental mobility of the tightly bound rubber component significantly decreases, whereas that of the loosely bound rubber component increases only slightly with increasing mixing time, and the segmental mobility in both components reaches a limiting magnitude characteristic of the respective components at $t$ (b.i.).

Figure 6 shows the relation between the mixing time and the fraction of the tightly bound rubber $\left(f_{\mathrm{C}}\right)$ in the bound rubber. The $f_{\mathrm{C}}$ is 0.35 at a very

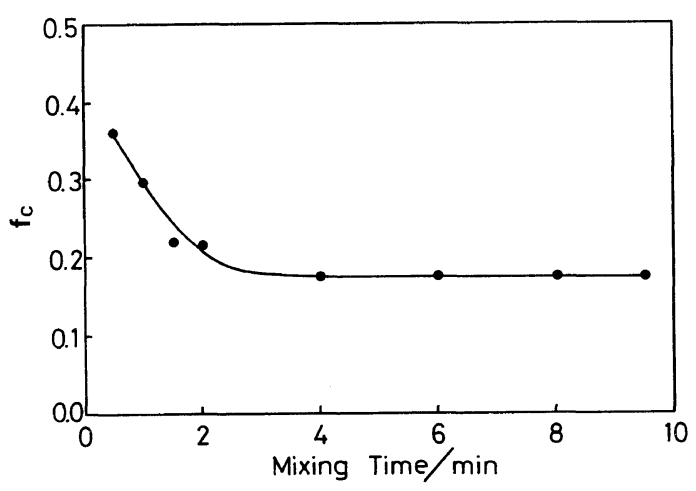

Figure 6. Fraction $\left(f_{\mathrm{C}}\right)$ of $T_{2 \mathrm{C}}$ component in the total bound rubber (B.R.) as a function of mixing time.

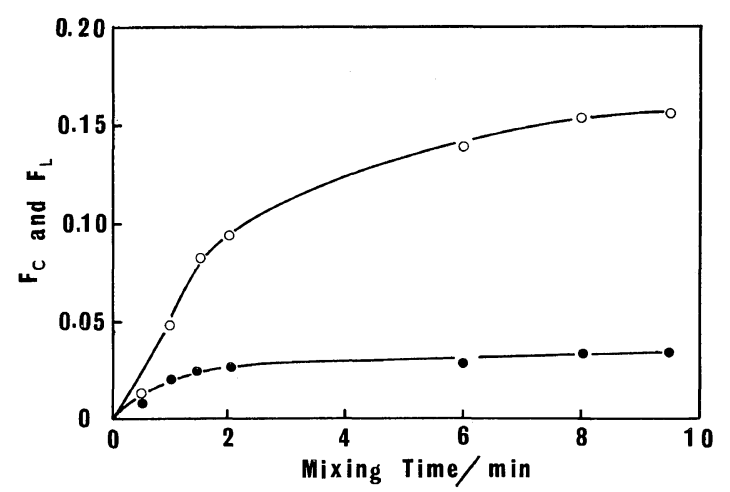

Figure 7. Fractions of the $T_{2 \mathrm{C}}$ component $\left(F_{\mathrm{C}}\right)$ and $T_{2 \mathrm{~L}}$ component $\left(F_{\mathrm{L}}\right)$ in the total filled rubber (F.R.) for composites as a function of mixing time:,$F_{\mathrm{C}} ; \bigcirc, F_{\mathrm{L}}$. short mixing time of $0.5 \mathrm{~min}$ and rapidly decreases with increasing mixing time until it approaches a constant value of about 0.18 at $t$ (b.i.), even though the total amount of the bound rubber increases steadily with mixing time until $8 \mathrm{~min}$ (Figure 2). Figure 7 shows the fractions of the loosely bound rubber $\left(F_{\mathrm{L}}\right)$ and the tightly bound rubber $\left(F_{\mathrm{C}}\right)$ in the total rubber contained in composite samples as a function of mixing time. Both $F_{\mathrm{C}}$ and $F_{\mathrm{L}}$ increase rapidly until $t$ (b.i.), then gradually, and finally reach limiting values at $8 \mathrm{~min}$. The increase in both components with mixing time is parallel to the dispersion of aggregated carbon black, as was observed in the total bound rubber component (Figure 2). This also suggests that the formation of both the loosely and tightly bound rubber components is primarily governed by the dispersion of carbon black or the contact of rubber segments with a new active surface of carbon black. Furthermore, the fact that $T_{2 \mathrm{C}}$ and $f_{\mathrm{C}}$ decrease significantly (Figures 5 and 6) but $T_{2 \mathrm{~L}}$ increases slightly (Figure 5) at the first stage of mixing has important implications concerning the mechanism of bound rubber formation. The tightly bound rubber is formed promptly when the rubber segments get in contact with a new surface of carbon black particles; however, the segmental mobility in this component is not yet so highly restricted at this stage as at the later stage (Figure 5). This indicates that the structure of the $T_{2 \mathrm{C}}$ phase formed varies with time toward the more constrained one. During this process some segments having less mobility in the $T_{2 \mathrm{~L}}$ phase formed seem to be transformed to the $T_{2 \mathrm{C}}$ component as suggested by the slight increase in the $T_{2 \mathrm{~L}}$. Simultaneously with these changes, the more loosely bound $T_{2 \mathrm{~L}}$ phase seems to grow rapidly on the preformed $T_{2 \mathrm{C}}$ phase at the expense of the non-bound rubber.

Ater $t$ (b.i.), the ratio of the tightly bound rubber to the loosely bound rubber and the segmental mobility in both components do not vary, although the total amount of both components increases slowly in this second stage. After about $8 \mathrm{~min}$, both the amount and mobility are not varied significantly.

\section{REFERENCES}

1. B. B. Boonstra, Polymer, 20, 691 (1979).

2. G. R. Cotten and B. B. Boonstra, Rubber Chem. 
Technol., 40, 829 (1967).

3. A. Voet, F. R. Cook, and A. K. Sircar, Rubber Chem. Technol., 44, 175 (1971).

4. C. M. Blow, Polymer, 14, 309 (1973).

5. J. O'Brien, E. Cashell, G. E. Wardell, and V. J. McBierty, Macromolecules, 9, 653 (1976).

6. S. Kaufman, W. P. Slichter, and D. D. Davis, J. Polym. Sci., A-2, 9, 829 (1971).

7. T. Nishi, J. Polym. Sci., Polym. Phys. Ed., 12, 685 (1974).

8. K. Fujimoto and T. Nishi, Nippon Gomu Kyokaishi, 43, 465 (1970).

9. G. Kraus and J. Dugone, Ind. Eng. Chem., 47, 1809 (1965).
10. J. G. Powles and J. H. Strange, Proc. Phys. Soc., 82 , 6 (1963).

11. S. Kaufman and D. J. Bunger, J. Magnetic Resonance, 3, 218 (1970).

12. P. R. Van Bunger, S. B. Turetzky, and P. E. Gunberg, Rubber Chem. Technol., 48, 577 (1975).

13. K. C. Beach, L. F. Comper, and V. E. Lowery, Rubber Age, 85, 253 (1959).

14. H. Palmgren, Eur. Rubber J., 156, 30 (1974).

15. D. W. McCall and D. R. Falcone, Trans. Faraday Soc., 66, 262 (1970).

16. D. E. Roberts and L. Mandelkern, J. Am. Chem. Soc., 77, 781 (1955). 